University of Nebraska - Lincoln

DigitalCommons@University of Nebraska - Lincoln

Faculty Publications, Department of Psychology

Psychology, Department of

June 2005

\title{
Religiosity and prosocial behaviours in adolescence: the mediating role of prosocial values
}

\author{
Sam A. Hardy \\ University of Nebraska-Lincoln \\ Gustavo Carlo \\ University of Nebraska-Lincoln, carlog@missouri.edu
}

Follow this and additional works at: https://digitalcommons.unl.edu/psychfacpub

Part of the Psychiatry and Psychology Commons

Hardy, Sam A. and Carlo, Gustavo, "Religiosity and prosocial behaviours in adolescence: the mediating role of prosocial values" (2005). Faculty Publications, Department of Psychology. 31.

https://digitalcommons.unl.edu/psychfacpub/31

This Article is brought to you for free and open access by the Psychology, Department of at DigitalCommons@University of Nebraska - Lincoln. It has been accepted for inclusion in Faculty Publications, Department of Psychology by an authorized administrator of DigitalCommons@University of Nebraska - Lincoln. 
Published in Journal of Moral Education, Vol. 34, No. 2, June 2005, pp. 231-249

\title{
Religiosity and prosocial behaviours in adolescence: the mediating role of prosocial values
}

\author{
Sam A. Hardy and Gustavo Carlo \\ University of Nebraska-Lincoln
}

This study examined the hypothesis that religiosity would be differentially related to six types of adolescent prosocial behaviour, and that these relations would be mediated by the prosocial value of kindness. Self-report data were collected from 142 high school students (63 per cent female; 91 per cent White; $M$ age $=16.8, S=.80$ ). Religiosity was a significant positive predictor of kindness, as well as compliant, anonymous and altruistic prosocial behaviour, but not public, dire and emotional prosocial behaviour. Associations between religiosity and both compliant and altruistic prosocial behaviours were mediated by kindness. Direct and indirect paths were found between religiosity and anonymous prosocial behaviour. Thus, partial support was found for the mediational hypothesis. Discussion focused on the utility of distinguishing among different types of prosocial behaviours and on the role of religion and values in promoting moral education.

Increasing concern among parents, schools, community leaders and policy makers regarding youth violence means that efforts to promote positive behaviours in teens are being welcomed (The Consortium on the Promotion of Social Competence, 1994). Given that most religions have teachings that emphasize care and compassion for others, religiosity (defined here as commitment to, identification with and involvement in a religion or system of religious beliefs) is a potential positive influence on adolescent prosocial behaviour. However, relatively little research has examined relations between religiosity and prosocial behaviour, and it has been almost solely conducted using college-age or adult samples (e.g., Darley \& Batson, 1973); hence, little is known about links between religiosity and prosocial behaviour, particularly among adolescents.

Scholars have proposed several reasons why religiosity might have an impact on adolescent prosocial behaviour (Regnerus, 2003; Smith, 2003). For example, it has been suggested that religion is a form of social capital (Smith, 1999; King \& Furrow, in press), provides opportunities for helping (Donahue \& Benson, 1995; Youniss et al., 1999; Mattis et al., 2000; Bridges \& Moore, 2002), acts as a source of social control (Annis, 1976; Batson et al., 1989) and provides reinforcement for 
prosocial behaviours (Ritzema, 1979; Ellison, 1992). However, the most widely recognized mechanism by which religiosity might influence prosocial behaviour is through socialization of prosocial values (Ritzema, 1979; Batson et al., 1985; Benson et al., 1989; Bernt, 1989; Ellison, 1992; Wilson \& Janoski, 1995; Smith, 1999; Youniss et al., 1999; Mattis et al., 2000). Specifically, religious texts (e.g., the Holy Bible, the Koran and the Talmud) and teachings (e.g., 'The golden rule') typically have a strong focus on doing good to others (Ritzema, 1979; Wuthnow, 1991) Firstly, the Holy Bible (1989 edition) makes mention of rewards associated with various caring behaviours such as giving alms (see Matthew 6: 3-4) and feeding the hungry (see Luke 14: 12-14), as well as punishments that follow lack of altruism (see Matthew 25: 41-46). Secondly, in the Holy Bible, Jesus Christ is hailed as a prosocial exemplar (see Matthew 8-9), and it is suggested that by acting altruistically one is doing what Christ would do, which is a key goal of Christian living (see Ephesians 5:2). Thirdly, the Holy Bible provides numerous stories and parables designed to promote altruism (e.g., the 'Good Samaritan'; see Luke 10). Similar teachings regarding prosocial values and behaviours can also be found in religious texts and doctrines of other religions, such as Buddhism (Batson et al., 1985; Habito, 2002). Thus, as Smith (2003) has proposed, religiosity provides youth with 'moral directives' to help guide their decisions and behaviour.

Empirical research on links between religiosity and prosocial behaviour is limited, and has not yielded simple, straightforward answers regarding whether or not, in what way, and to what extent religiosity is associated with prosocial behaviour (for reviews, see Batson \& Ventis, 1982; Batson et al., 1985; Benson et al., 1989; Donahue \& Benson, 1995; Argyle, 2000; Bridges \& Moore, 2002; Regnerus, 2003). In these studies, prosocial behaviour has typically been assessed using the following types of measures: self-report measures of everyday prosocial behaviours, such as holding a door open for a stranger (e.g., Benson et al., 1987; Chau et al., 1990; Furrow et al., 2004; Maclean et al., 2004; King \& Furrow, in press); self-report measures of volunteerism, involvement in relief efforts, or charitable behaviours such as donating money (e.g., Wilson \& Janoski, 1995; Youniss et al, 1999; Mattis et al., 2000); and behavioural measures of prosocial behaviour, such as emergency bystander situations (e.g., Darley \& Batson, 1973; Annis, 1976). Some studies have found religiosity to be positively associated with prosocial behaviour (e.g., Benson et al., 1987; Ellison, 1992; Smith, 1999; Youniss et al., 1999 Mattis et al., 2000; Smith \& Faris, 2002; Furrow et al., 2004; King \& Furrow, in press). However, others have found religiosity either to be unrelated to prosocial behaviour (e.g., Darley \& Batson, 1973; Annis, 1976; Sundeen \& Raskoff, 1995), or only related for some people in some situations (e.g., Batson \& Gray, 1981; Batson et al., 1989; Bernt, 1989; Chau et al., 1990; Hansen et al., 1995; Wilson \& Janoski, 1995; Wilson \& Musick, 1997; Maclean et al., 2004). Thus, although there does seem to be a connection between religiosity and prosocial behaviour, it is likely complex, varying across individuals, situations and types of behaviour.

Despite inconsistencies in the strength of associations between religiosity and prosocial behaviour across studies, there do seem to be certain general patterns in these relations. For example, Batson and colleagues have suggested that links between religiosity and prosocial behaviour might differ according to the type of religious orientation individuals have (extrinsic, intrinsic or quest). Individuals with an extrinsic religious orientation view religion as a means to other ends, such as social status; those with an intrinsic religious orientation see religion as an intrinsically motivating end in itself; and people with quest religious orientation characterize religion as a process involving questioning and re-examining values and beliefs (Batson \& Gray, 1981). The strongest links between religion and prosocial behaviour tend to be reported for the quest and intrinsic orientations, as opposed to the extrinsic orientation (Batson et al., 1985; however, see Maclean et al., 2004 for an exception). Batson and colleagues also posited that links between religiosity and prosocial behaviour may vary according to whether or not the measure of prosocial behaviour is self-report or behavioural (stronger associations for self-report measures, which they suggested are possibly due to social desirability bias; see Batson \& Ventis, 1982, for review).

More recently, some scholars have proposed that relations between religiosity and prosocial behaviour might also differ according to the type of prosocial behaviour being assessed (Bernt, 1989; Hansen et al., 1995). For example, measures of prosocial behaviour might assess emergency (e.g., Batson and colleagues' emergency bystander situations; Darley \& Batson, 1973) or non-emergency (e.g., volunteering; Bernt, 1989) types of helping. In general, religiosity seems to be more strongly and consistently linked to prosocial behaviour in non-emergency situations (e.g., Benson et al., 1987; Bernt, 1989; Ellison, 1992; Smith, 1999; Mattis et al., 2000; Smith \& Faris, 2002) than emergency situations (e.g., Annis, 1976; Darley \& Batson, 1973). Also, prosocial behaviours might differ in the extent to which they are self-initiated (e.g., volunteering) or not (e.g., being asked for help; Hansen et al., 1995). Hansen and colleagues (1995) found that Intrinsic religious orientation was positively associated with self-report frequency of volunteering, while quest religious orientation was positively associated with a behavioural measure of helping when asked. More research is needed to assess the extent to which self-initiated and compliant prosocial behaviours are linked to religiosity. It should also be noted that the different results reported by studies using self-report versus behavioural measures of prosocial behaviour might stem not only from differences in mode of administration but also in the type of behaviour assessed (e.g., self-report measures have typically assessed more voluntary, non-emergency behaviours, while behavioural measures have generally assessed emergency behaviours, or situations where help is solicited).

Scholars such as Bernt (1989) and Hansen et al. (1995) have called for researchers to seek more discriminatory measures of prosocial behaviour in order to better elucidate links with religiosity. In line with this request, prosocial behaviour researchers have suggested that prosocial behaviour should not be thought of as a unitary construct, but rather a multi-dimensional construct with variation among the dimensions in their relations to other constructs, such as religiosity (Batson, 1998; Eisenberg \& Fabes, 1998; Carlo \& Randall, 2001). Further, recent advances 
in research on prosocial behaviour have identified multiple types of prosocial behaviours (Carlo \& Randall, 2002). Specifically, compliant prosocial behaviour is helping when asked, public prosocial behaviour is helping in the presence of others, anonymous prosocial behaviour is helping anonymously, dire prosocial behaviour is helping in emergency situations, emotional prosocial behaviour is helping in emotionally evocative circumstances and altruistic prosocial behaviour is voluntary helping motivated by concern for others rather than anticipation of personal rewards. Carlo and Randall (2002) designed and validated a 23-item measure for assessing these six types of prosocial behaviours in adolescence. Interestingly, the subscales of this measure were all uncorrelated with social desirability.

As mentioned previously, most of the studies of religion and prosocial behaviour reviewed above used adult samples, particularly college students. Research linking religiosity and adolescent behaviour has typically emphasized the influence of religious involvement on negative behaviours, such as delinquency (Benson, 1993), sexual risk-taking (Wilcox et al., 2001; Hardy \& Raffaelli, 2003) and substance use (Bahr et al., 1998). However, of the few studies that have examined links between religiosity and prosocial behaviour in adolescence, most have found higher religiosity to be associated with higher rates of prosocial behaviours (for reviews see Benson et al., 1989; Donahue \& Benson, 1995; Bridges \& Moore, 2002; Regnerus, 2003). For example, in two different large samples, Benson and colleagues (Benson et al., 1986; Benson et al., 1987) reported significant positive correlations between religiosity and various forms of helping (e.g., self-reported willingness to help an older woman who drops her groceries). Similarly, researchers from Fuller Theological Seminary (Furrow et al., 2004; King \& Furrow, in press) recently found positive relations between adolescent religiosity and several moral outcomes, including everyday helping and prosocial responding.

Other studies have looked specifically at relations between religiosity and adolescent volunteer service. For example, Smith and Faris (2002) found that among a large sample of twelfth-graders (twelfth-graders in the United States tend to be 17-19 years of age), various aspects of religiosity (attendance, importance of religion, years of church youth group and denomination) were positively related to volunteer community service, even after controlling for various demographics. Others have reported similar positive relations between religiosity and volunteer service in adolescence (e.g., Benson, 1993; Smith, 1999; Trusty \& Watts, 1999; Youniss et al., 1999). However, Sundeen and Raskoff (1995) found no association between religious commitment and level of volunteerism among teens. Given the limited research on religion and prosocial behaviour in adolescence, the present study is a much needed empirical examination of relations between these important constructs.

\section{The present study}

If religiosity is linked to prosocial behaviour in adolescence, as the research reviewed above seems to suggest, what is the nature of the association? One plausible mechanism for associations between religiosity and prosocial behaviour is that religious involvement is a source for socialization of prosocial values, and that acquisition of prosocial values in turn leads to prosocial behaviour. As mentioned earlier, religious texts (e.g., the Holy Bible, the Koran and the Talmud) and teachings (e.g., 'The golden rule') typically include messages promoting prosocial values (Ritzema, 1979; Batson et al., 1985; Habito, 2002). As empirical support for the connection between religious involvement and prosocial values, Schwartz and colleagues (Schwartz \& Huismans, 1995; Roccas \& Schwartz, 1997) reported that, across multiple large adult samples from various cultures, self-reported level of religiousness was positively correlated with scores on the Benevolence subscale of the Schwartz Value Survey (the Benevolence subscale includes items for helpful, honest, forgiving, loyal and responsible). Similarly, religious attendance correlated positively with Benevolence scores for a large German sample, including a subsample of individuals aged 14-29 years (Schwartz \& Huismans, 1995). In short, reading and hearing religious teachings may provide opportunities and incentives for learning and accepting prosocial values.

Several theorists have conceptualized values as motives and standards for behaviour (Rokeach, 1973; Schwartz \& Howard, 1984; Feather, 1990). Prior research linking constructs such as values, beliefs and attitudes to behaviours has been somewhat inconsistent (for a review see Kristiansen \& Hotte, 1996). It is suspected that the often disappointingly weak relations between values and behaviour are largely due to the overly abstract nature of values, with their sometimes ambiguous connections to behaviour (Schwartz \& Howard, 1984; Kristiansen \& Hotte, 1996) However, Bond and Chi (1997) found support for links between prosocial values and behaviour among adolescents in their study of Chinese teens aged 11-17 years. Using the Universalism, Benevolence and Conformity subscales of the Schwartz Value Survey as an indicator of prosocial values, they found a significant positive correlation between prosocial values and an index of 49 different civic behaviours (e.g., telling the truth, respecting and being polite to teachers, protecting water sources). In a related study involving college-age young adults, environmental values (e.g., protecting the environment), when important to the self, were positively associated with environmentally friendly behaviours (Verplanken \& Holland, 2002). Hence, there is some support for associations between prosocial values and behaviours, making prosocial values plausible mediators of relations between religiosity and prosocial behaviour. Thus, the first hypothesis for the present study was that the prosocial value of kindness would mediate relations between religiosity and prosocial behaviours. In simpler terms, it was expected that religious involvement would lead to greater acceptance of prosocial values, which would in turn provide teens with direction and motivation towards prosocial behaviour. This mechanism has been postulated, but has not been directly examined before.

The second hypothesis for the current study was that relations between religiosity and prosocial behaviour would differ depending on the type of prosocial behaviour. Given the lack of research on religiosity and prosocial behaviour that has used complex multidimensional measures of prosocial behaviour, it was difficult to 
anticipate the pattern of relations between religiosity and the six types of prosocial behaviour described earlier (compliant, public, dire, anonymous, emotional and altruistic). However, prior literature on prosocial behaviours has provided some hints as to how religiosity might be differentially related to these forms of prosocial behaviour. In particular, there has been some discussion in the literature regarding the relative role of situational versus individual influences on helping behaviour. For example, in a classic study by Latané and Darley (1970), personality factors (e.g. social responsibility) did not predict helping in an emergency situation (an experimenter pretending to have an epileptic seizure and requesting help). Thus, in emergency situations, situational influences may be more relevant than personality variables such as values and religiosity.

More recently, Snyder and Ickes (1985) have suggested that situations can be differentiated according to how 'strong' or 'weak' they are. Strong situations 'provide salient cues to guide behaviour and have a fairly high degree of structure and definition', whereas weak situations 'do not offer salient cues to guide behaviour and are relatively unstructured and ambiguous' (Snyder \& Ickes, 1985, p.904). Thus, strong situations might be more influenced by situational factors (e.g., degree of risks, perceived costs or benefits of helping) while weak situations allow for more influence of individual differences (e.g., personality, cognitive abilities, values)

The studies of religiosity and prosocial behaviour reviewed earlier do seem to provide some support for the notion that in certain situations (that is, strong or emergency situations), personality variables (e.g., religiosity) have less impact on prosocial behaviour than in other situations (that is, weak or non-emergency situations). For example, significant associations are more consistently found between religiosity and volunteering and other non-emergency forms of prosocial behaviour (e.g., Benson et al., 1987; Bernt, 1989; Ellison, 1992; Youniss et al., 1999; Smith \& Faris, 2002), than between religiosity and helping in emergency situations (Darley \& Batson, 1973; Annis, 1976). Thus, it was hypothesized that religiosity would be unrelated to dire and emotional prosocial behaviour (which seem to correspond more to strong situations and emergency helping)

Regarding anonymous and public prosocial behaviours, religion may provide a social context where public helping is reinforced, but religious teachings tend to emphasize the benefits of anonymous helping. Additionally, it seems that public prosocial behaviours would correspond more to strong situations, as discussed earlier (there is social pressure to help), while anonymous prosocial behaviours seem more congruent with weak situations (there is less, if any, social pressure to help). Hence, it was expected in the current study that religiosity would be positively associated with anonymous, but unrelated to public prosocial behaviours.

Altruistic prosocial behaviour has been defined as 'behaviours motivated by the primary desire to benefit others' (Carlo, in press, p.6). It is motivated by other-oriented affect (sympathy) or internalized principles (e.g., kindness), and often undertaken at a cost to the helper (Eisenberg \& Fabes, 1998; Carlo \& Randall, 2001; Carlo, in press). Thus, on the one hand, it overlaps with dire prosocial behaviour because it can occur in emergency situations. However, altruism is frequently based on internalized prosocial values and has been found to be positively associated with internalized moral reasoning (Carlo \& Randall, 2002). Therefore, since re ligiosity was posited as a source for the socialization of prosocial values, it was hypothesized in the present study that religiosity would be positively associated with altruistic prosocial behaviour.

Lastly, it was particularly difficult to anticipate relations between religiosity and compliant prosocial behaviour. A few studies have examined links between religiosity and what seem to be compliant prosocial behaviours (e.g., Batson \& Gray, 1981; Hansen et al., 1995). Both studies cited here used Batson's Religious Orientation Scale, and found the quest orientation to be positively associated with helping in situations where helping is solicited. It has been noted that individuals with a quest orientation might be those who have internalized religious values to a greater extent (Batson et al., 1989). However, the present study did not use the Religious Orientation Scale as a measure of religiosity; thus, it was not entirely clear how these prior results would apply. Further, conceptually, it seems compliant prosocial behaviour should be motivated more by approval-oriented thinking rather than internalized principles. Additionally, compliant prosocial behaviour situations seem to be consonant with Snyder and Ickes' (1985) description of strong situations (that is, as situations characterized by 'salient cues to guide behaviour and

... a fairly high degree of structure and definition'; 1985, p.904). Thus, in the current study it was anticipated that religiosity would be unrelated to compliant prosocial behaviours.

In summary, it was expected that religiosity would be positively associated with altruistic and anonymous prosocial behaviours, but unrelated to dire, emotional, public and compliant prosocial behaviour. Further, it was anticipated that the specific pattern of relations between the prosocial value of kindness and the various types of prosocial behaviour would be similar to the pattern for links between religiosity and prosocial behaviours. In other words, it was hypothesized that kindness would be significantly associated with altruistic and anonymous prosocial behaviours, but not dire, emotional, public and compliant types. Lastly, it was hypothesized that the prosocial value of kindness would mediate relations between religiosity and prosocial behaviours.

\section{Method}

\section{Participants}

The sample included 142 students (63\% female; $91 \%$ White; $M$ age $=16.8, S D$ $=.80$ ) at a midwestern USA public high school. Approximately $82 \%$ of the teens were living with both parents, who had never been divorced or separated. Roughly $70 \%$ of the fathers and $70 \%$ of the mothers had at least a 4 -year college degree. Eighteen per cent of the students reported no religious affiliation, $78 \%$ were Christian (Catholic, Protestant or other Christian), and $4 \%$ were affiliated with some other religious group (Jewish, Muslim, Bahá'í and Wicca). 


\section{Procedures}

Researchers recruited participants from several classes at a single midwestern public high school. Participation was voluntary, although some students received extra credit for their involvement. Students interested in participating were asked by the researcher to take home a recruitment letter and informed consent forms to their parent(s). The cooperating school received a monetary donation to the general school fund, participating teachers received a monetary donation for their classroom and the students who participated were compensated \$10. Data were collected via self-report questionnaires administered to the students in their classrooms. There were no missing data on religiosity, prosocial values or prosocial behaviours.

\section{Measures}

Religiosity. There has been much debate and confusion in the past regarding how to best define and measure religiosity (Benson, 2004). As a result, there are numerous measures of religiosity (Hill \& Hood, 1999). However, often researchers attempt to measure one or more of the following: religious salience or commitment; religious activity or involvement; and religious identity. In line with this, a composite was created using 7 items that seem to jointly tap these three areas of religiosity $(\alpha=.93)$. One item (How important is religion in your life?) was based on a scale from 1 (not at all important) to 5 (very important), and two items (How often do you go to church? How often do you attend church related activities (such as youth activities) other than worship services?) utilized a scale from 1 (never) to 5 (more than once a week). The remaining four items (I am a spiritual person; I practise my religion; My faith never deserts me during hard times; My faith makes me who I am) used a scale from 1 (very much unlike me) to 5 (very much like me). These last four items were taken from the spirituality subscale of Values in Action Inventory of Strengths for Youth (VIA-Youth, Peterson \& Seligman, 2004). The composite was created by averaging across all items.

Kindness. Kindness seems congruent with the universal prosocial value type Schwartz (1992) labelled Benevolence and defined as involving 'concern for the welfare of close others in everyday interaction' (p.11). The prosocial value of kindness was measured in the present study using the 10-item kindness subscale ( $\alpha$ $=.79$ ) of the Values in Action Inventory of Strengths for Youth (VIA-Youth, Peterson $\&$ Seligman, 2004). The response scale was from 1 (very much unlike me) to 5 (very much like me; sample item: I enjoy being kind to others). The composite was created by averaging across all items.

Prosocial behaviours. These were assessed using the Prosocial Tendencies Measure (Carlo \& Randall, 2002), which assesses six types of prosocial behaviour (compliant, public, anonymous, dire, emotional and altruistic) using a scale from 1 (does not describe me at all) to 5 (describes me greatly). Factor analyses and pi-
Table 1. Descriptives and correlations

\begin{tabular}{|c|c|c|c|c|c|c|c|c|c|c|c|}
\hline Variable & 1 & 2 & 3 & 4 & 5 & 6 & 7 & 89 & $9 \quad M$ & $S D$ & Range \\
\hline 1. Gender & & & & & & & & & & & \\
\hline 2. Religiosity & $.17^{\star}$ & & & & & & & & 3.17 & 1.11 & $1-5$ \\
\hline 3. Kindness & $.33^{\star \star \star \star}$ & ${ }^{*} .33^{\star \star}$ & & & & & & & 3.97 & .49 & $1-5$ \\
\hline 4. Compliant PB & .14 & $.21^{\star}$ & $.52^{\star \star}$ & & & & & & 3.84 & .80 & $1-5$ \\
\hline 5. Public PB & $-.23^{\star \star}$ & .002 & -.04 & .07 & & & & & 2.17 & .85 & $1-5$ \\
\hline 6. Anonymous PB & 3.01 & $.36^{\star \star \star}$ & $.28^{\star \star}$ & $.23^{\star \star}$ & .03 & & & & 2.82 & .84 & $1-5$ \\
\hline 7. Dire PB & .06 & .10 & $.30^{\star \star \star}$ & $\star .40^{\star \star \star}$ & * .10 & $.24^{\star \star}$ & & & 3.58 & .82 & $1-5$ \\
\hline 8. Emotional PB & $.15^{+}$ & $.15^{+}$ & $.54^{\star \star \star \star}$ & $\star .54^{\star \star \star \star}$ & *. .07 & $.20^{\star}$ & $.69^{\star \star \star}$ & & 3.62 & .89 & $1-5$ \\
\hline 9. Altruistic PB & .21 & $.22^{\star \star}$ & $.28^{\star \star}$ & $.21^{\star}$ & $-.52^{\star \star \star \star}$. & ${ }^{\star} .17^{\star}$ & .08 & $.15^{+}$ & 3.95 & .62 & $1-5$ \\
\hline
\end{tabular}

lot testing in previous studies (Carlo \& Randall, 2002) revealed the following subscales for these six forms of prosocial behaviour: 2 items for compliant prosocial behaviour ( $\alpha=.81$; sample item: When people ask me to help them, I don't hesitate); 4 items for public prosocial behaviour ( $\alpha=.85$; sample item: I can help others best when people are watching me); 5 items for anonymous prosocial behaviour $(\alpha=.82$; sample item: I think that helping others without them knowing is the best type of situation); 3 items for dire prosocial behaviour ( $\alpha=.76$; sample item: I tend to help people who are in a real crisis or need); 5 items for emotional prosocial behaviour ( $\alpha=.88$; sample item: I respond to helping others best when the situation is highly emotional); and 6 items for altruistic prosocial behaviour $(\alpha=.69$; sample item: I often help even if I don't think I will get anything out of helping). For each subscale a composite score was created by averaging across all items in that subscale. This measure has shown adequate reliability and validity in previous studies, including test-retest reliability as well as validity with other measures of prosocial behaviour and with measures of empathy and prosocial moral reasoning (Carlo \& Randall, 2002; Carlo et al., 2003).

\section{Results}

Main analyses plan

Mediational analyses were utilized to test whether kindness (the prosocial value assessed in the present study) mediated relations between religiosity and prosocial behaviours. Separate mediational analyses were conducted for each of the six types of prosocial behaviour using hierarchical linear regression and the procedures outlined by Baron and Kenny (1986). Firstly, a linear regression was used to assess the association between religiosity and kindness, controlling for gender. Secondly, for each type of prosocial behaviour, a two-step hierarchical regression model was conducted to predict prosocial behaviour. In the first step, gender and religiosity were entered. On the second step, kindness was entered. For mediation to occur, religiosity must be significantly associated with kindness in the first regression 


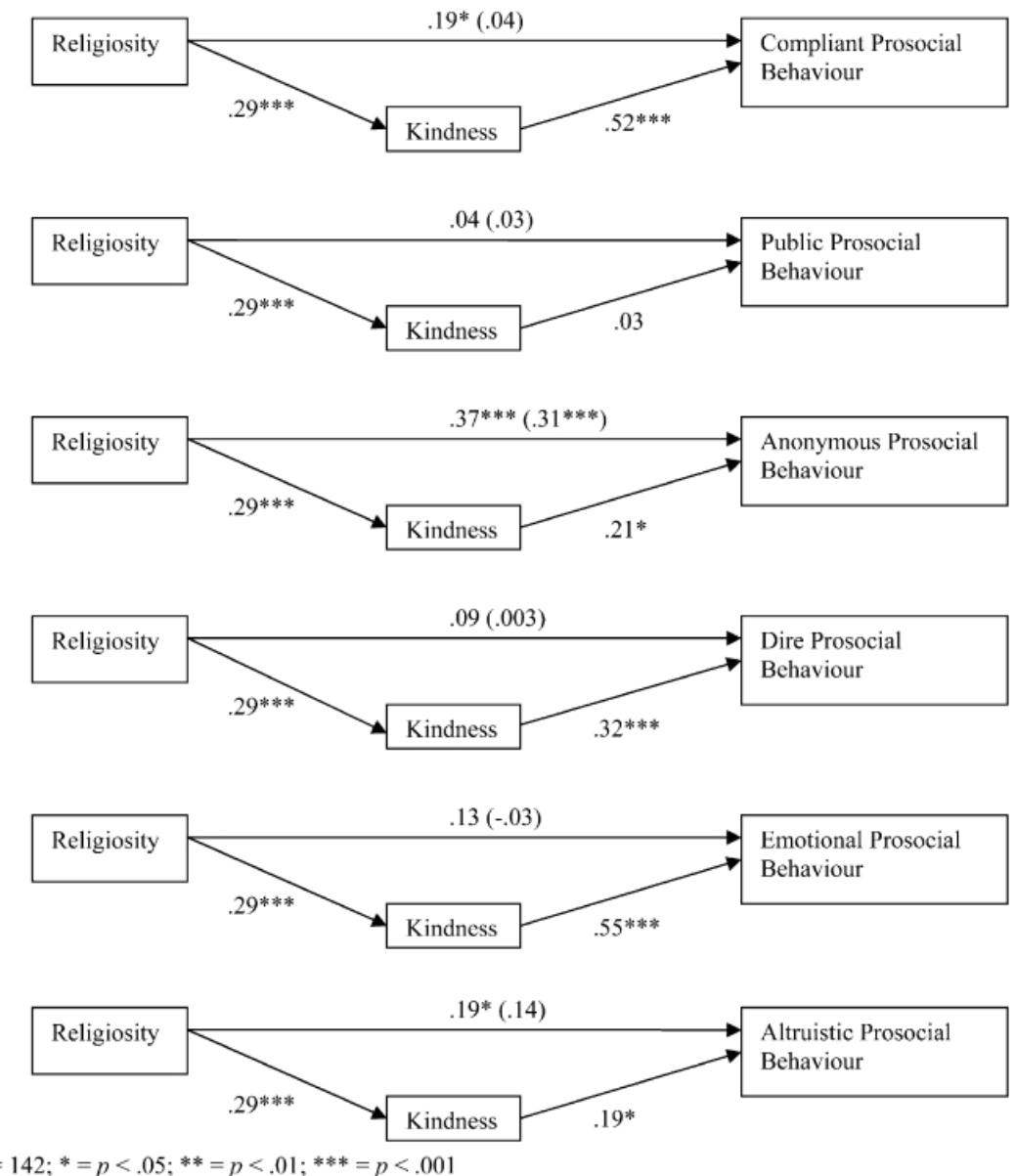

Note: Values in parenthesis are the standardized beta coefficients for these paths after addition of kindness in the regression models predicting prosocial behaviours. Gender was entered as a control in all analyses.

model discussed above. Additionally, in the second regression, religiosity must be associated with prosocial behaviour in the first step of the model; then, when kindness is entered, kindness must significantly predict prosocial behaviour, while religiosity must become nonsignificant. If these conditions hold, it suggests that the mediator (kindness) accounts for a significant amount of the variation in the outcome (prosocial behaviour) predicted by the criterion (religiosity).

\section{Preliminary analyses}

Descriptive statistics and correlations for study variables are displayed in Table 1. Regarding prosocial behaviour, adolescents reported highest levels for altruis- tic prosocial behaviour tendencies, followed by compliant, emotional, dire, anonymous and public, respectively. Religiosity was positively correlated with kindness, and compliant, anonymous and altruistic prosocial behaviours. Lastly, there were positive correlations between kindness and all forms of prosocial behaviour except public, to which it was unrelated.

A one-way ANOVA was conducted to assess gender differences on study variables. Females reported higher levels of religiosity, $F(1,140)=4.01, p<.05$; kindness, $F(1,140)=16.87, p<.001$; and altruistic prosocial behaviour, $F(1,140)$ $=6.65, p<.05$, than males. On the other hand, higher levels of public prosocial behaviour were reported for males than for females, $F(1,140)=7.75, p<.01$. There were no significant gender differences found for compliant, $F(1,140)=$ $2.74, p=n s$; anonymous, $F(1,140)=.02, p=n s$; dire, $F(1,140)=.48, p=n s$; or emotional, $F(1,140)=3.15, p=n s$, prosocial behaviours. Given the gender differences found, gender was entered as a statistical control in all regression analyses reported below.

Analyses were conducted to assess relations between marital status, father's education level, mother's education level and the main study variables. First, an ANOVA was used to test for differences in study variables by marital status (as measured by whether or not the parents were married and had never been divorced or separated). There were no significant mean marital status differences in any of the study variables. Second, bivariate correlations were conducted between father's education level, mother's education level and the study variables. Education level for fathers and mothers was measured using a 7-point scale from 1 (elementary or junior high school) to 7 (professional or graduate degree). There were no significant correlations between any of the study variables and mother's or father's education level.

\section{Main analyses}

Regression analyses are presented in Figure 1. In the first regression analysis, religiosity was a significant positive predictor of kindness. Next, a series of hierarchical linear regression analyses was conducted to assess relations between religiosity and the six types of prosocial behaviour, as well as to examine whether kindness mediated these relations.

There was a significant positive association between religiosity and compliant prosocial behaviour. Kindness was entered in the second step, and was a significant positive predictor of compliant prosocial behaviour. Also, with the addition of kindness in the model, religiosity became nonsignificant. Thus, the prosocial value kindness mediated relations between religiosity and compliant prosocial behaviour.

Religiosity was not significantly related to public prosocial behaviour. Therefore, there was no possibility for mediation. Furthermore, in the second step, with the addition of kindness in the model, neither religiosity nor kindness significantly predicted public prosocial behaviour. 
Higher religiosity significantly predicted higher anonymous prosocial behaviour. However, when kindness was entered in the second step, both religiosity and kindness were significant positive predictors of anonymous prosocial behaviour. Hence, although kindness did not mediate relations between religiosity and anonymous prosocial behaviours, there was a direct and an indirect path by which religiosity was linked to anonymous prosocial behaviour.

Religiosity was not a significant predictor of dire prosocial behaviour. Thus, mediation was not possible. When kindness was entered in the second step, it was positively associated with dire prosocial behaviours, but religiosity remained nonsignificant.

There was not a significant association between religiosity and emotional prosocial behaviour. Therefore, there was no possibility for mediation. With the addition of kindness on the second step, religiosity remained nonsignificant, but kindness was a significant positive predictor of emotional prosocial behaviour.

Higher religiosity was significantly associated with higher altruistic prosocial behaviour. Also, kindness was a significant positive predictor of altruistic prosocial behaviour in step two, whereas religiosity became nonsignificant. Thus, the prosocial value kindness mediated the association between religiosity and altruistic prosocial behaviour.

\section{Discussion}

The purposes of the present study were to examine whether relations between religiosity and prosocial behaviour in adolescence would differ according to type of prosocial behaviour, and to test whether these relations would be mediated by prosocial values. Specifically, it was anticipated that religiosity would be positively associated with altruistic and anonymous prosocial behaviours, but not significantly related to dire, emotional, compliant and public prosocial behaviours. This hypothesis was partially supported.

Religiosity was associated positively with compliant, anonymous and altruistic prosocial behaviours, but was not significantly predictive of public, dire and emotional prosocial behaviours. In line with prior research (Bernt, 1989; Hansen et al., 1995), anonymous and altruistic prosocial behaviours might be influenced more by individual factors such as religiosity, whereas public, dire and emotional prosocial behaviours might be more impacted by situational factors (similar to emotionally evocative situations). Moreover, altruistic (that is, helping out of concern for others rather than anticipation of reward) and anonymous (helping in anonymous situations) helping seem to be the types of prosocial behaviours more explicitly endorsed by religious texts and teachings. Somewhat contrary to expectation, religiosity was positively related to compliant prosocial behaviour. Compliant prosocial behaviours (that is, helping when asked) do seem consonant with the types of opportunities frequently offered by religious involvement (e.g., being asked to assist fellow church members). Additionally, compliant prosocial behaviour in previous research (Hansen et al., 1995) entailed requests for help in emergencies or oth- er immediate situations, whereas some requests for help are less urgent. Thus, there is likely variability in the contexts of compliant prosocial behaviours.

The pattern of associations between adolescent religiosity and prosocial behaviour reported in the present study might elucidate inconsistencies often found when examining these variables in college student or adult samples. In general, studies that have failed to find significant positive associations between religiosity and prosocial behaviour among adult samples have typically used behavioural measures of prosocial behaviour (e.g., Darley \& Batson, 1973). These behavioural measures are often simulated emergency bystander situations (Darley \& Batson, 1973). The present study found that higher religiosity was linked to higher altruistic and anonymous prosocial behaviour, but was unrelated to dire and emotional prosocial behaviour, which are the two types of prosocial behaviour most similar to the emergency bystander situations. In essence, it may be that one reason behavioural measures of prosocial behaviour are often unrelated to religiosity is that they are tapping into a form of prosocial behaviour that commonly occurs in 'strong' environments (Snyder \& Ickes, 1985), and is less influenced by individual characteristics such as religiosity.It was also anticipated that, like religiosity, kindness would be significantly associated with altruistic and anonymous prosocial behaviours, but not dire, emotional, public and compliant types. However, it was found that kindness was significantly positively associated with all forms of prosocial behaviour except public prosocial behaviour, to which it was unrelated. It seems plausible that the prosocial value of kindness would be unrelated to public prosocial behaviour; essentially, public prosocial behaviour is the type of prosocial behaviour most likely to be motivated by selfish or egoistic motives (e.g., wanting to look good in front of peers; Carlo \& Randall, 2002), rather than the other-oriented value of kindness. Indeed, approval-oriented prosocial moral reasoning was found to be related positively to public prosocial behaviours (Carlo \& Randall, 2002). The finding that kindness was positively related to the other five forms of prosocial behaviour is congruent with prior theory (Grusec \& Kuczynski, 1997) and research (e.g., Bond \& Chi, 1997) linking prosocial values and behaviours in adolescence.

The hypothesis that relations between religiosity and prosocial behaviours would be mediated by kindness was also partially supported. Specifically, mediation was found for compliant and altruistic prosocial behaviours, but not for anonymous prosocial behaviour. Thus, kindness, which was associated with religiosity, accounted for systematic variance in both compliant and altruistic prosocial behaviour. These findings are consistent with scholars' assertions that religiosity may not be a sufficient predictor of prosocial behaviour. Rather, some forms of prosocial behaviours are the result of individuals' manifestations of internalized values such as kindness (Eisenberg \& Fabes, 1998; Carlo, in press). In contrast, religiosity has a direct and indirect path in predicting anonymous prosocial behaviour; both religiosity and kindness were necessary to predict this form of prosocial behaviour. In other words, kindness did not account for a significant amount of the association between religiosity and anonymous prosocial behaviour, meaning that religiosity has some unique contribution to anonymous prosocial behaviour beyond that attributable to kindness. 
In addition to the main analyses, preliminary analyses revealed several interesting gender differences. For example, congruent with prior research on religiosity in adolescence (e.g., Johnston et al., 1999), girls reported higher religiosity than boys. Also, in line with previous studies of prosocial behaviour types (e.g., Carlo \& Randall, 2002), girls were higher on altruistic prosocial behaviour, boys were higher on public prosocial behaviour and there were no gender differences in dire prosocial behaviour. Moreover, girls reported more kindness than boys. Taken together, these results are consistent with gender socialization theorists' expectations regarding relatively strong gender intensification effects in adolescence (Eisenberg \& Fabes, 1998).

There were several limitations to the present study. First, all measures were selfreport; thus, we assessed adolescents' perceptions of their values and behaviours rather than their actual values and behaviours. Some scholars have expressed concerns about self-report measures. For example, use of self-report measures in studies of religiosity and positive social behaviour may result in social desirability bias (Batson \& Ventis, 1982). However, not only have some researchers not found social desirability effects (Watson et al., 1986), but it is suspected that any correlations that are found between religiosity and social desirability might be the result of social desirability measures being confounded with religiosity (Watson et al., 1986; Trimble, 1997). In other words, social desirability measures might actually be partially tapping into aspects of religiosity itself. Additionally, previous studies using the measure of prosocial behaviour utilized in the present study have found it to be uncorrelated with social desirability (Carlo \& Randall, 2002). Regardless, given potential limitations (such as social desirability bias) inherent in self-report measures, the present results should be interpreted with caution.

A second limitation of the present study is that the correlational nature of the data prohibited strict examination of causality. Thus, it cannot be determined whether religiosity actually had a causal impact on prosocial values and behaviour, or whether prosocial values had a causal impact on prosocial behaviour. There are other possible explanations for the present results. For example, it is possible that there are certain personality traits that lead individuals to be both more religious and more prosocial. Alternatively, it is also feasible that engaging in prosocial behaviour leads to higher levels of prosocial values and to greater involvement in religious activities. Future research should seek to utilize research methodologies that better allow for causal interpretability of relations between religiosity, prosocial values and prosocial behaviour.

Third, the findings of the present study might not be generalizable to all teens worldwide. The majority of the teens in the present sample were White, European Americans, living with both biological or adoptive parents who had at least a 4-year college degree. Furthermore, the results might have more application to Christian teens than those affiliated with other religions. This is because teens in the present sample were primarily Christian, and the measure of religiosity may be more applicable to Christian adolescents (e.g., some religious groups may not emphasize regular attendance at worship services or church youth activities, or these opportunities may not even be available). Thus, although the present sample was fairly representative of adolescents from a small city in the midwestern region of the United States, further research is needed with larger, more diverse adolescent samples.

Despite these limitations, there are potential applied implications of the results of this study. Primarily, the present findings suggest that religiosity may help promote prosocial behaviour by fostering prosocial values in adolescents. This is in line with Smith's (2003) proposition that religiosity provides teens with 'moral directives' to guide their lives. If religiosity does effectively promote prosocial values, a better understanding of the mechanisms involved may provide useful guidance to parents, schools, community leaders and policy makers, regarding ways to facilitate prosocial values development in youth. There are likely several possible mechanisms by which religiosity may be linked to the development of prosocial values. For example, as mentioned earlier, religious texts and teachings extol prosocial values (Ritzema, 1979; Wuthnow, 1991). Youth may also learn to value kindness through their involvement in service opportunities provided by religious groups (Youniss \& Hart, 2002). Through such involvement, as well as having personal 'spiritual experiences' and developing relationships with positive role models, youth internalize prosocial values and integrate them into their identities (Smith, 2003). In this way these values become a part of who they are and permeate many aspects of their lives (e.g., emotions, perceptions, decision-making, desires, interests, commitments and relationships). More detailed exploration of links between religiosity and the development of prosocial values is warranted in order to better understand mechanisms such as these.

Religion is only one of many possible sources of prosocial values and behaviours. Other socialization agents, such as families, schools and youth organizations such as 4-H (an educational youth development programme sponsored by the US Department of Agriculture) and Boy Scouts of America may also have great potential to positively impact teens. For example, all of these agents can teach teens to understand the importance of prosocial values and behaviours. However, some mechanisms that foster prosocial values and behaviours may be unique to religiosity (Smith, 2003). According to Smith (2003), social scientists tend to be reductionistic regarding matters of religion. They attempt to reduce the divine or spiritual to the sociological (e.g., social control or social class) or psychological (e.g., cognitive development or coping mechanisms). In reality, religion may positively influence youth in ways not reducible to existing sociological or psychological theories, and ways not easily transferable to other socialization agents. Examples of such ways are spiritual experiences and relationships to divine beings. On the other hand, religious and non-religious socialization experiences that jointly promote positive moral values and behaviours may have powerful impact on prosocial development of youth.

It should also be noted that religion is not always a positive influence on youth development. Thus, cautions should be taken by those seeking to draw guidance from religious groups regarding positive youth development. Firstly, not all re- 
ligious groups promote positive values and behaviours. In fact, some religious groups actually encourage - although not always explicitly - prejudice and violence (Argyle, 2000). Secondly, even if the doctrines of a certain religious group extol positive values and behaviour, this does not mean all the followers of that group will abide by those doctrines. In other words, caution should be taken when choosing who to emulate. Thirdly, not all mechanisms by which religious groups promote positive development may be desirable to non-religious organizations For example, some religious groups encourage uncritical obedience as a means to positive youth outcomes (Argyle, 2000).

The results of the present study suggest that religiosity may facilitate prosocial behaviour in adolescents by promoting the prosocial value of kindness. However, readers should be warned against oversimplifying possible links between religiosity, prosocial values and prosocial behaviour. Firstly, it is feasible that multiple values (e.g., kindness, fairness and honesty) are involved in facilitating prosocial behaviour - not just kindness. Secondly, in addition to values, a multitude of other influences on prosocial behaviour (e.g., gender, parenting and situational factors) have been identified by researchers (Eisenberg \& Fabes, 1998; Carlo, in press) Thirdly, it is tenable that some religious teens behave prosocially without truly internalizing prosocial values. Instead, they have other motives for their prosocial actions, such as positive peer pressure, positive reinforcement for acting prosocially, gaining the approval of others or fear of the suggested consequences for not being altruistic (Ritzema, 1979). Thus, the present study is just one small step forward in understanding the roles of religiosity and values on adolescent prosocial development.

\section{Acknowledgments}

This research was funded by grants from the Mayerson Foundation, the American Psychological Association and the John Templeton Foundation to Gustavo Carlo, Professor of Psychology in the Department of Psychology at the University of Nebraska-Lincoln. The authors appreciate the assistance and cooperation of Lincoln Southeast High School staff, teachers and students. Special thanks to Rob McEntarffer and his students for their assistance.

\section{References}

Annis L. V. Emergency helping and religious behavior (1976) Psychological Reports, 39, $151-158$.

Argyle M. (2000) The psychology of religion: an introduction. New York: Routledge.

Bahr S. J., Maughan S. L., Marcos A. C., and Li B. Family, religiosity and the risk of adolescent drug use (1998) Journal of Marriage and the Family, 60, 979-992.

Baron R. M. and Kenny D. A. The moderator-mediator variable distinction in social psychological research: conceptual, strategic and statistical considerations (1986) Journal of Personality and Social Psychology, 51(6), 1173-1182.

Batson C. D. Altruism and prosocial behavior (1998) in: D. T. Gilbert \& S. T. Fiske (Eds) Hand- book of social psychology, (Vol2) (4th edn) New York: McGraw-Hill, 282-316.

Batson C. D. and Gray R. A. Religious orientation and helping behavior: responding to one's own or to the victim's needs? (1981) Journal of Personality and Social Psychology, 40(3), $511-520$.

Batson C. D. and Ventis W. L. (1982) The religious experience: a social-psychological perspective. New York: Oxford University Press.

Batson C. D., Oleson K. C., Weeks J. L, Healy S. P., Reeves P. J., Jennings P., and Brown T. Religious prosocial motivation: is it altruistic or egoistic? (1989) Journal of Personality and Social Psychology, 57(5), 873-884.

Batson C. D., Schoenrade P. A., and Pych V. Brotherly love or self-concern?: behavioural consequences of religion (1985) in: L. B. Brown (Ed.) Advances in the psychology of religion Elmsford, NY: Pergamon Press, 185-208.

Benson P. L. (1993) The troubled journey: a portrait of 6th-12th grade youth. Minneapolis: Search Institute.

Benson P. L. Emerging themes in research on adolescent spiritual and religious development (2004) Applied Developmental Science, 8(1), 47-50.

Benson P. L., Donahue M. J., and Erickson J. A. Adolescence and religion: a review of the literature from 1970 to 1986 (1989) Research in the Social Scientific Study of Religion, 1, 153-181.

Benson P. L., Williams D. L., and Johnson A. L. (1987) The quicksilver years: the hopes and fear of young adolescents. San Francisco, CA: Harper \& Row.

Benson P. L., Yeager R. J., Wood P. K., Guerra M. J., and Manno B. V. (1986) Catholic high schools: their impact on low-income students. Washington DC: National Catholic Education Association.

Bernt F. M. Being religious and being altruistic: a study of college service volunteers (1989) Personality and Individual Differences, 10(6), 663-669.

Bond M. H. and Chi V. M. Values and moral behavior in mainland China (1997) Psychologia, 40, 251-264.

Bridges L. J and Moore K. A. (2002) Religious involvement and children's well-being: what research tells us (and what it doesn't). Available online at: http://www.childtrends.org (accessed 1 October 2002).

Carlo G. Care-based and altruistically-based morality, (in press) in: M. Killen \& J. G. Smetana (Eds.) Handbook of moral development. Mahwah, NJ: Lawrence Erlbaum Associates.

Carlo G. and Randall B. A. Are all prosocial behaviors equal? A socioecological developmental conception of prosocial behavior (2001) in: F. Columbus (Ed.) Advances in psychology research, (Vol. 2) Huntington: Nova Science Publishers, 151-170.

Carlo G. and Randall B. A. The development of a measure of prosocial behaviors for late adolescents (2002) Journal of Youth and Adolescence, 31(1), 31-44

Carlo G., Hausmann A., Christiansen S., and Randall B. A. Sociocognitive and behavioral correlates of a measure of prosocial tendencies for adolescents (2003) Journal of Early Adolescence, 23(1), 107-134.

Chau L. L., Johnson R. C., Bowers J. K., Darvill T. J., and Danko G. P. Intrinsic and extrinsic religiosity as related to conscience, adjustment, and altruism (1990) Personality and Individual Differences, 11(4), 397-400.

Darley J. M. and Batson C. D. 'From Jerusalem to Jericho': a study of situational and dispositional variables in helping behavior (1973) Journal of Personality and Social Psychology, 27(1), $100-108$.

Donahue M. J. and Benson P. L. Religion and the well-being of adolescents (1995) Journal of Social Issues, 51(2), 145-160.

Eisenberg N. and Fabes R. A. Prosocial development (1998) in: W. Damon (Series Ed.) \& N. 
Eisenberg (Vol. Ed.) Handbook of child psychology. Vol. 3. Social, emotional, and personality development, (5th edn) New York: John Wiley, 701-778.

Ellison C. G. Are religious people nice people? Evidence from the National Survey of Black Americans (1992) Social Forces, 71(2), 411-430.

Feather N. T. Bridging the gap between values and actions: recent applications of the expectancy-value model (1990) in: E. T. Higgins \& R. M. Sorrentino (Eds) Handbook of motivation and cognition: foundations of social behaviour, (Vol. 2) New York: The Guildford Press, 151-191.

Furrow J. L., King P. E., and White K. Religion and positive youth development: identity, meaning, and prosocial concerns (2004) Applied Developmental Science, 8(1), 17-26.

Grusec J. E. and Kuczynski L. (Eds) (1997) Parenting and children's internalization of values: a handbook of contemporary theory. New York: John Wiley.

Habito R. L. F. Compassion out of wisdom: Buddhist perspectives from the past toward the human future (2002) in: S. G. Post, L. G. Underwood, J. P. Schloss \& W. B. Hurlbut (Eds) Altruism \& altruistic love: science, philosophy, and religion in dialogue . London: Oxford University Press.

Hansen D. E., Vandenberg B., and Patterson M. L. The effects of religious orientation on spontaneous and nonspontaneous helping behaviors (1995) Personality and Individual Differences, 19(1), 101-104.

Hardy S. A. and Raffaelli M. Adolescent religiosity and sexuality: an investigation of reciprocal influences (2003) Journal of Adolescence, 26, 731-739.

Hill P. C. and Hood R. W. Jr. (Eds) (1999) Measures of religiosity. Birmingham: Religious Education Press.

Johnston L. D., Bachman J. G., and O’Malley P. M. (1999) Monitoring the future: questionnaire responses from the nation's high school seniors. Ann Arbor: Institute for Social Research.

King P. E. and Furrow J. L. Religion as a resource for positive youth development: religion, social capital, and moral outcomes, (in press) Developmental Psychology

Kristiansen C. M. and Hotte A. M. Morality and the self: implications for the when and how of value-attitude-behaviour relations (1996) in: L. Seligman, J. M. Olson \& M. P. Zanna (Eds) The psychology of values: the Ontario Symposium, (Vol. 8) Mahwah, NJ: Lawrence Erlbaum Associates, $77-105$

Latané B. and Darley J. M. (1970) The unresponsive bystander: why doesn't he help?. New York: Appleton-Century-Crofts.

Maclean A. M., Walker L. J., and Matsuba M. K. Transcendence and the moral self: identity integration, religion, and moral life (2004) Journal for the Scientific Study of Religion, 43(3) 429-437.

Mattis J. S., Jagers R. J., Hatcher C. A., Lawhon G. D., Murphy E. J., and Murray Y. F. Religiosity, volunteerism, and community involvement among African American men: an exploratory analysis (2000) Journal of Community Psychology, 28(4), 391-406.

Peterson C. and Seligman M. E. P. (2004) Character strengths and virtues: A handbook and classification. Washington DC: American Psychological Association.

Regnerus M. D. Religion and positive adolescent outcomes: a review of research and theory (2003) Review of Religious Research, 44(4), 394-413.

Ritzema R. J. Religiosity and altruism: faith without works? (1979) Journal of Psychology \& Theology, 7(2), 105-113.

Roccas S. and Schwartz S. H. Church-state relations and the association of religiosity with values: a study of Catholics in six countries (1997) Cross-Cultural Research, 31(4), 356-375.

Rokeach M. (1973) The nature of human values. New York: The Free Press.

Schwartz S. H. Universals in the content and structure of values: theoretical advances and empiri- cal tests in 20 countries (1992) in: M. P. Zanna (Ed.) Advances in experimental social psychology, (Vol. 25) Orlando, FL: Academic Press, 1-65.

Schwartz S. H. and Howard J. A. Internalized values as motivators of altruism (1984) in: E. Staub, D. Bar-Tal, J. Karylowski \& J. Reyowski (Eds) Development and maintenance of prosocia behavior: international perspectives on positive morality . New York: Plenum, 229-255.

Schwartz S. H. and Huismans S. Value priorities and religiosity in four Western religions (1995) Social Psychology Quarterly, 58(2), 88-107.

Smith C. Theorizing religious effects among American adolescents (2003) Journal for the Scientific Study of Religion, 42(1), 17-30.

Smith C. and Faris R. (2002) Religion and American adolescent delinquency, risk behaviors and constructive social activities. Chapel Hill, NC: National Study of Youth and Religion.

Smith E. S. The effects of investment in the social capital of youth on political and civic behavior in young adulthood: a longitudinal analysis (1999) Political Psychology, 20(3), 553-580.

Snyder M. and Ickes W. Personality and social behaviour (1985) in: G. Lindzey \& E. Aronson (Eds) Handbook of social psychology, (3rd edn) New York: Random House, 883-948.

Sundeen R. A. and Raskoff S. A. Teenage volunteers and their values (1995) Nonprofit and Voluntary Sector Quarterly, 24, 337-357.

The Consortium on the Promotion of Social Competence. The school-based promotion of social competence: theory, research, practice, and policy (1994) in: R. J. Haggerty, L. R. Sheroud, N. Garmezy, \& M. Rutter (Eds), Stress risks and resilience in children and adolescents: processes, mechanisms, and interventions. Cambridge: Cambridge University Press, 268-316.

The Holy Bible (King James Version) (1989) Salt Lake City, UT: The Church of Jesus Christ of Latter-Day Saints.

Trimble D. E. The Religious Orientation Scale: review and meta-analysis of social desirability effects (1997) Educational \& Psychological Measurement, 57(6), 970-986.

Trusty J. and Watts R. E. Relationship of high school seniors' religious perceptions and behavior to educational, career, and leisure variables (1999) Counseling \& Values, 44(1), 30-40.

Verplanken V. and Holland R. W. Motivated decision making: effects of activation and self-centrality of values on choices and behavior (2002) Journal of Personality and Social Psychology, 82(3), 434-447.

Watson P. J., Morris R. J., Foster J. E.m and Hood R. W. Religiosity and social desirability (1986) Journal for the Scientific Study of Religion, 25(2), 215-232.

Wilcox B. L., Rostosky S. S., Randall B.m and Wright M. L. C. Reasons for hope: a review of research on adolescent religiosity and sexual behavior (2001) in: B. D. Whitehead, B. L. Wilcox \& S. S. Rostosky (Eds), Keeping the faith: the role of religion and faith communities in preventing teen pregnancy. Washington DC: National Campaign to Prevent Teen Pregnancy, $31-82$.

Wilson J. and Janoski T. The contribution of religion to volunteer work (1995) Sociology of Religion, 56(2), 137-152.

Wilson J. and Musick M. Who cares? Toward an integrated theory of volunteer work (1997) American Sociological Review, 62, 694-713

Wuthnow R. (1991) Acts of compassion: caring for others and helping ourselves. Princeton, NJ: Princeton University Press.

Youniss J. and Hart D. Motivation, values, and civic participation. paper presented at the Democracy Collaborative-Knight Civic Engagement Project Consultation Meeting (2002) Washington DC, 24 October.

Youniss J., McLellan J. A., and Yates M. Religion, community service, and identity in American youth (1999) Journal of Adolescence, 22, 243-253. 